\title{
Expression of Fraser syndrome genes in normal and polycystic murine kidneys
}

\author{
Larissa Kerecuk • David A. Long • Zahabia Ali • \\ Corina Anders • Maria Kolatsi-Joannou • \\ Peter J. Scambler • Adrian S. Woolf
}

Received: 27 May 2011 /Revised: 16 December 2011 / Accepted: 20 December 2011 /Published online: 1 February 2012

(C) IPNA 2012

\begin{abstract}
Background Fraser syndrome (FS) features renal agenesis and cystic kidneys. Mutations of FRASI (Fraser syndrome 1) and FREM2 (FRAS1-related extracellular matrix protein 2) cause FS. They code for basement membrane proteins expressed in metanephric epithelia where they mediate epithelial/mesenchymal signalling. Little is known about whether and where these molecules are expressed in more mature kidneys.

Methods In healthy and congenital polycystic kidney (cpk) mouse kidneys we sought Frem 2 expression using a LacZ reporter gene and quantified Fras family transcripts. Fras1 immunohistochemistry was undertaken in cystic kidneys from $c p k$ mice and PCK (Pkhdl mutant) rats (models of autosomal recessive polycystic kidney disease) and in wildtype metanephroi rendered cystic by dexamethasone.
\end{abstract}

L. Kerecuk • D. A. Long · Z. Ali • M. Kolatsi-Joannou •

P. J. Scambler

UCL Institute of Child Health,

London, UK

L. Kerecuk

Department of Pediatric Nephrology,

Birmingham Children's Hospital,

Birmingham, UK

C. Anders $\cdot$ A. S. Woolf

School of Biomedicine, University of Manchester and Manchester Children's Hospital, Manchester Academic Health Science Centre, Manchester, UK

\section{A. S. Woolf $(\bowtie)$}

Developmental and Regenerative Medicine Research Group,

University of Manchester,

Michael Smith Building, Oxford Road,

Manchester M13 9PT, UK

e-mail: adrian.woolf@manchester.ac.uk
Results Nascent nephrons transiently expressed Frem 2 in both tubule and podocyte epithelia. Maturing and adult collecting ducts also expressed Frem2. Frem 2 was expressed in cpk cystic epithelia although Frem2 haploinsufficiency did not significantly modify cystogenesis in vivo. Fras 1 transcripts were significantly upregulated, and Frem3 downregulated, in polycystic kidneys versus the non-cystic kidneys of littermates. Fras1 was immunodetected in $c p k$, PCK and dexamethasone-induced cyst epithelia.

Conclusions These descriptive results are consistent with the hypothesis that Fras family molecules play diverse roles in kidney epithelia. In future, this should be tested by conditional deletion of FS genes in nephron segments and collecting ducts.

Keywords Basement membrane - Cyst - Development . Fras $1 \cdot$ Frem $2 \cdot$ LacZ $\cdot$ Reporter gene

\section{Introduction}

Fraser syndrome (FS) is an autosomal recessive disease characterised by cryptophthalmos (hidden eyes), cutaneous syndactyly (fused digits), ambiguous genitalia and renal and upper respiratory (larynx and trachea) tract malformations [1-3]. Up to about $30 \%$ of cases have bilateral renal agenesis, while others have one or more of the following: unilateral renal agenesis and uni- or bilateral cystic, dysplastic or hypoplastic kidneys [2, 3]. FS is rare, occurring in around 11/100,000 stillbirths and 0.4/ 100,000 live births, and a significant subset of the latter die in the first year with renal and/or respiratory failure $[2,3]$. Survival to old-age is, however, possible when functional kidney tissue is present [4]. 
Some individuals with FS have homozygous mutations of either FRAS1 (Fraser syndrome 1) [5] or FREM2 (FRAS1-related extracellular matrix protein 2) [6]. Mice with homozygous null mutations of either gene have developmental anomalies phenocopying human FS [5-8]. The penetrance of renal agenesis is strain dependant, approaching 100\% in the C57BL-6 J background [8]. Outbred mice with Fras 1 or Frem 2 mutations have a lower incidence of renal agenesis and, in this context, mice with compound Fras 1/Frem 2 mutations have kidneys with multiple cysts arising from the distal nephron and collecting ducts, as respectively assessed by uromodulin expression and binding of Dolichos biflorus lectin [6].

Fras 1 and Frem 2 proteins localise in embryonic basement membranes where they are thought to mediate physical (e.g. in skin) or signalling (e.g. in metanephric kidney induction) interactions between epithelia and adjacent mesenchymal cells $[9,10]$. Delivery of Fras1 to the plasma membrane is mediated by interaction with glutamate receptor-interacting protein 1 (Grip1) [11,12]. Extracellularly, Fras1 and Frem2 associate with each other and also with a related molecule called Frem1 [9, 10, 13, 14]. Mice with homozygous mutations of Frem1 [15] or Gripl [11] phenocopy human FS, and humans with FREM1 mutations have an FS-like syndrome with prominent hindgut and renal tract anomalies [16]. Frem3 is another member of the Fras protein family [10, 17], but human FREM3 mutations have yet to be reported.

Little is known about whether and where molecules encoded by FS genes might be expressed in postnatal kidneys. In this study, we investigated Frem 2 expression in healthy and congenital polycystic kidney (cpk) mouse kidneys using a $L a c Z$ reporter gene and quantified Fras family transcripts. Fras 1 immunohistochemistry was undertaken in cystic kidneys from $c p k$ mice and $P C K$ ( $P k h d 1)$ mutant rats [models of autosomal recessive polycystic kidney disease (PCD)] and in wild-type metanephroi rendered cystic by dexamethasone exposure.

\section{Materials and methods}

Experiments were undertaken in accordance with the UK Home Office Animal (Scientific Procedures) Act 1986. In the $m y^{K S T}$ mouse, Frem 2 is mutated by a gene trap, and $L a c Z$ reporter gene expression mimics tissue patterns of endogenous Frem 2 transcripts [6]. Homozygous $m y^{K S T}$ mutants have the myencephalic blebs phenotype featuring external eye anomalies, syndactyly and renal malformations, similar to human FS. For simplicity, we hereafter refer to this allele as Frem $2^{\text {LacZ }}$ and, as a prelude to studies described below, it was propagated in a C57BL-6 J background for over six generations by crossing heterozygous $\left(\right.$ Frem $\left.2^{\text {LacZ/+ }}\right)$ with wild-type mice. For some experiments, we bred the Frem $2^{L a c Z}$ allele into mice carrying the $c p k$ allele, also maintained on a C57BL-6 J background. $c p k$ mice have a mutation of cystin which encodes a protein localised to the primary cilium [18]. Although a mutation of a homologous human gene has yet to be reported, murine $c p k / c p k$ kidneys anatomically resemble those found in human autosomal recessive polycystic kidney disease (PKD) (ARPKD) [19].

We used the X-gal technique to generate an easily detected blue-coloured precipitate wherever the LacZ reporter gene was expressed from the Frem2 locus [6]. This was undertaken in whole mounts, and histology sections were prepared from these, as described [20]. Using this protocol, no unspecific staining was observed in foetal or adult kidneys lacking the Frem $^{\text {LacZ }}$ allele as has been demonstrated by Yuan et al. [20] and also in the Results described below (see Fig. 2g, h; Fig. 3e-h). Paraffin-embedded kidneys were sectioned (thickness $5 \mu \mathrm{m}$ ) and, after dewaxing, were variously counterstained with (1) haematoxylin to detect cell nuclei, (2) antibody to uromodulin to detect thick ascending limbs of loops of Henle and (3) antibody to aquaporin-2 to detect collecting ducts [20-22]. Other sections were reacted with anti-Fras 1 antibody (HPA011281; Sigma, St. Louis, MO) raised in rabbits against a 102 amino acid human epitope that is $87 \%$ conserved in murine Fras1. Primary antibodies were detected using appropriate secondary antibodies and a peroxidase-based system, generating a brown colour [20-22]. Representative staining patterns for at least three organs for each time point were obtained. In cystic kidneys, we quantified the proportions of cross-sectional areas of kidneys which were occupied by cysts, as described [22].

Glomerular numbers per kidney were counted after gentle acid dissociation of 2-week-old kidneys, as previously described [23]. RNA was extracted from wild-type and $c p k / c p k$ kidneys, and levels of Fras-related (i.e. Fras 1, Frem1, Frem2, Frem 3 and Grip1) were measured using the RT ${ }^{2}$ Profiler PCR Array system, as previously described [22]. Levels were factored for a panel of transcripts encoded by housekeeping genes, as described [22]. Student's $t$-test was used to compare data sets.

After determining that Fras1 was prominently expressed in $c p k$ cysts (see Results), Fras1 immunohistochemistry was undertaken in two other cystic models. The first of these was embryonic day 13 (E13) wild-type CD1 mouse metanephroi explanted in organ culture and grown in serum-free, defined media containing $0.47 \mu \mathrm{M}$ dexamethasone, as previously described [22]. In this model, which may represent a paradigm for the modulation of cystogenesis by glucocorticoid "foetal programming" [24], nephrons become cystic after 6 days in culture [22]. The second model was 8-week-old wild-type and PCK homozygous mutant kidneys (Charles River) which contain predominantly distal nephron and 
collecting duct cysts [25]. These rats carry a mutation in Pkhd1, the homologous gene being mutated in human ARPKD [26].

\section{Results}

Frem $2^{\text {LacZ/+ }}$ kidneys are structurally normal

In preliminary experiments, we noted that E16 homozygous Frem $2^{\text {LacZ/LacZ }}$ mutant mice lacked kidneys (data not shown). Conversely, no gross anomalies of shape or size of either kidneys or lower renal tracts were observed in several tens of autopsies of foetal and postnatal heterozygous (Frem $2^{\text {LacZ/+ }}$ ) mice. With regard to kidney weights in 14-dayold postnatal mice, after nephrogenesis has finished [27], there was no significant difference $(P=0.61)$ between wild-type and heterozygous organs [mean \pm standard deviation (SD); Frem $2^{+/+}, 42 \pm 7 \mathrm{mg}(n=8)$; Frem $2^{\text {LacZ/+ }}$, $40 \pm 5 \mathrm{mg}(n=9)]$. Similarly, there was no significant difference $(P=0.45)$ between estimated numbers of glomeruli per kidney between the two genotypes at this stage $\left[\right.$ Frem $2^{+/+}$, $10.6 \pm 1.2 \times 10^{3}\left(n=13 ;\right.$ Frem $\left.^{\text {Lac }} / /+11.1 \pm 1.5 \times 10^{3}(n=17)\right]$. Frem $2^{\text {LacZ/+ }}$ kidneys could not be distinguished from wild-type littermate organs based on histology (data not shown). These results suggest that Frem 2 haploinsuffiency does not overtly affect nephrogenesis.

Frem 2 is expressed in epithelia in the nephogenic cortex

In mice, layers of nephrons are generated in the superficial (nephrogenic) cortex beginning in the foetal period and continuing until the middle of the first postnatal week
[27, 28]. During this process, termini of ureteric bud (UB) branches are flanked by primitive nephrons which have been induced to differentiate into epithelia from renal mesenchymal cells. In histology sections of E16, E18 and postnatal day 3 (P3) Frem $2^{\text {LacZ/+ }}$ kidneys, transgene expression was detected in the nephrogenic cortex in UB stalks and tips (Fig. 1a). Differentiating nephrons adjacent to UBs also expressed $L a c Z$, most prominently in the distal limb of the S-shaped body where the proximal tubule forms (Fig. 1a). Subsets of podocytes in maturing, capillary-loop stage glomeruli also expressed the transgene (Fig. 1a, b). At these stages, cortical (Fig. 1b) and medullary (Fig. 1c) collecting ducts also expressed LacZ. These histological expression patterns had counterparts that became evident upon inspection of the whole mount preparations. At E16, expression was prominent in arborising UB branches and collecting ducts (Fig. 2a, b), and urothelium in the ureter also expressed Frem2 at this stage (Fig. 2a). Clusters of blue "leopard spots" (each cluster representing a UB terminus surrounded by primitive nephrons) were detected on outer surfaces of E18 Frem $2^{\text {LacZ/+ }}$ and P3 kidneys (Fig. 2c, e), while sagittal sections at these stages revealed prominent staining in the nephrogenic zone (Fig. 2d, f). As expected, at P3 (Fig. 2g, h) and at other stages (data not shown), no specific signal was detected after X-gal staining of wild-type kidneys.

Frem 2 is expressed in diverse structures in the normal adult kidney

Inspection of whole mounts at 21 days and 6 weeks (Fig. 2i, j and data not shown) revealed minimal transgene expression in the outer cortex of the kidney. In contrast,

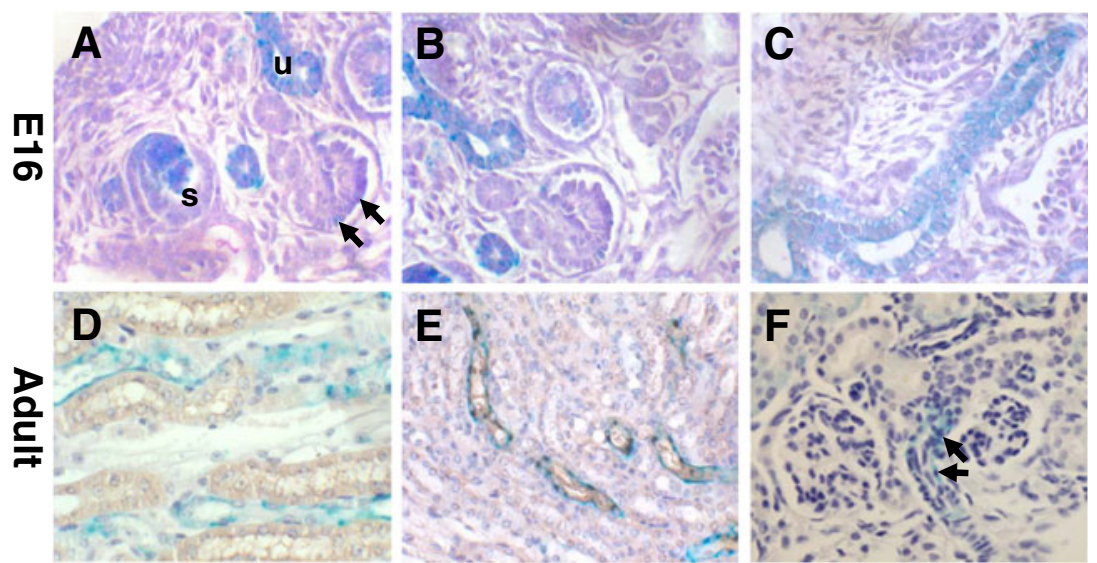

Fig. 1 LacZ expression in histology sections of Frem $2^{\text {LacZ/+ }}$ kidneys. All sections were from kidneys stained using the $\mathrm{X}$-gal procedure, with a light-blue colour indicating sites of transgene expression. All sections were counterstained with haematoxylin (dark-blue nuclei). a-c Sections from the same embryonic day (E16) metanephric kidney, moving from superficial to deeper areas in the organ. In the nephrogenic (a) and deeper cortex (b), Frem $2 / \mathrm{LacZ}$ was expressed in ureteric bud branches $(u)$, Sshaped bodies $(s)$ and subsets of podocytes (arrows) of immature glomeruli. The transgene was expressed by large medullary collecting ducts $(\mathbf{c})$. d-e Adult kidneys. In the outer medulla (d), tubules expressing LacZ lie alongside thick ascending limbs of loops of Henle which express uromodulin (brown). Tubules which express Frem 2/LacZ also expressed aquaporin-2 (brown), defining them as collecting ducts (e). f In adult kidneys, podocytes do not express Frem2/LacZ. Transgene expression is noted in smooth muscle cells in a nearby arteriole (arrows). a-e magnification $\times 40$, $\mathbf{f}$ magnification $\times 63$ 


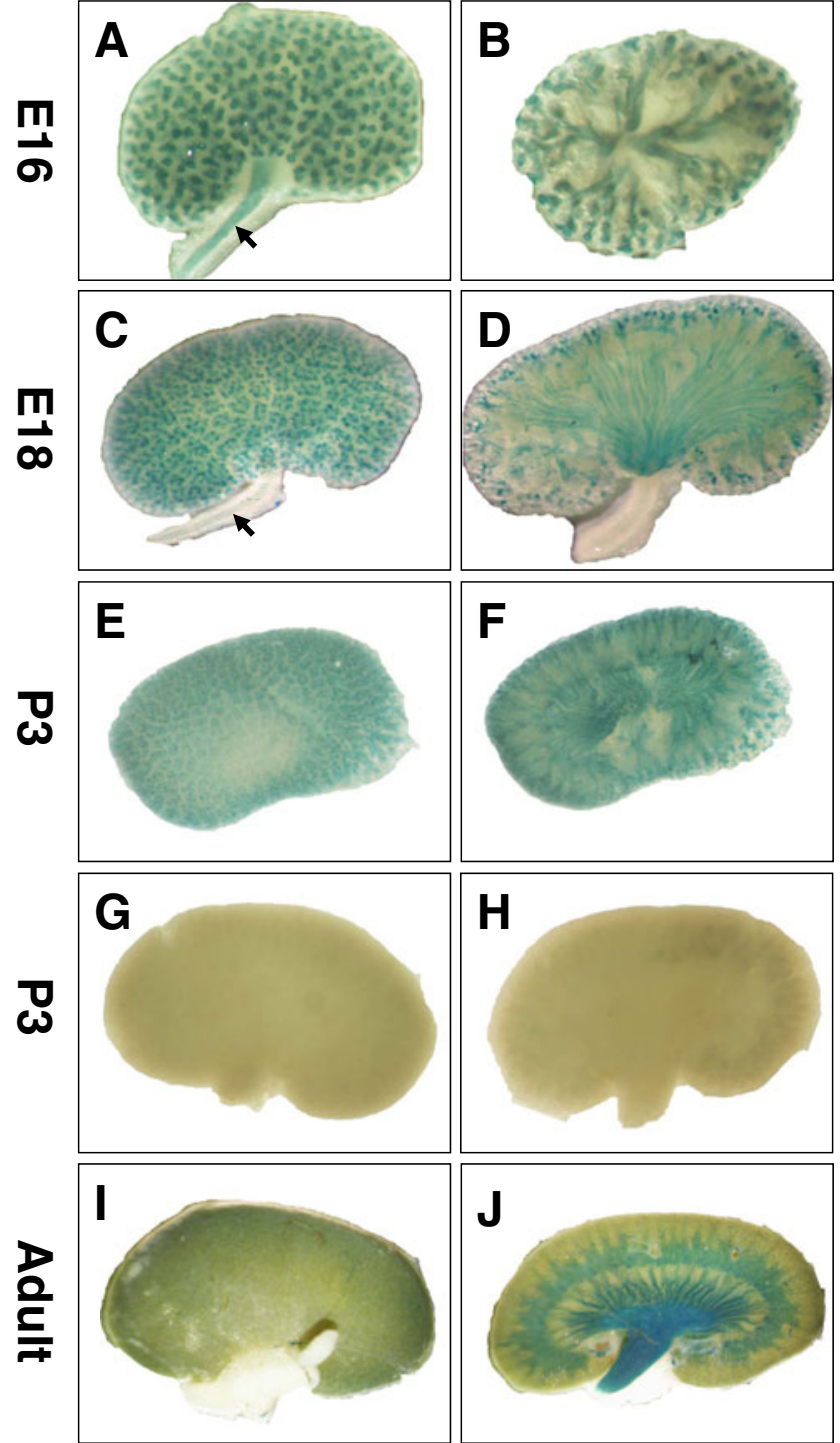

Fig. 2 Whole-mount X-gal staining. All images are of Frem2 $2^{\text {LacZ/+ }}$ kidneys, except for $\mathbf{g}$ and $\mathbf{h}$ which are wild-type organs. $\mathbf{a}, \mathbf{c}, \mathbf{e}, \mathbf{g}, \mathbf{i}$ Views of outside surfaces of kidneys; all other images are of sagittal sections. At E16, the arborising ureteric bud branches and their tips in the nephrogenic zone express the reporter gene (blue colour). Note that the urothelium of the ureter also expresses Frem $2 / \mathrm{LacZ}$ at this stage (arrow). At E18, the external pattern becomes more complex, with clusters of blue, each representing a ureteric bud tip flanked by the forming nephrons. A similar pattern is noted at postnatal day $3(P 3)$, representing a later wave of nephrogenesis. In the adult kidney, transgene expression is most prominent in the outer medulla and papilla, representing collecting ducts (compare with Fig. 1e). Radial blue streaks in the outer cortex represent expression in small arteries (compare with Fig. 1f). g, h Wild-type kidneys; X-gal staining did not result in a significant blue signal

a band of prominent expression was detected in the outer medulla, and there was also marked expression in the deep medulla/papilla. Frem $2^{\text {LacZ }}$ was expressed in medullary tubules which immunostained for aquaporin-2 but not uromodulin, defining these structures as collecting ducts and excluding the possibility that thick ascending limbs of loops of Henle expressed Frem2/LacZ (Fig. 1d, e). Walls of renal arteries expressed the transgene (Figure 1f), but transgene expression was not detected within mature glomerular tufts (Fig. 1f).

Fras 1 transcripts are upregulated and Frem 3 downregulated in $c p k$ kidneys

Maintained on a C57BL-6 J background, $c p k / c p k$ mice undergo two phases of kidney cystogenesis [21, 29]: (1) during the first postnatal week, proximal tubules form small cysts; (2) thereafter, cysts derived from collecting ducts cause massive nephromegaly, with death from renal excretory failure occurring from the fourth postnatal week onwards. Thus, for our analyses, we studied day 14 postnatal $c p k / c p k$ mice, at which time the histology is dominated by collecting duct cysts but the animals are not yet overtly unwell from uraemia. As assessed by qPCR, there was a significant $(P=0.025) 3.5$-fold upregulation of Frasl, based on our comparison of four $\mathrm{cpk} / \mathrm{cpk} \mathrm{Frem2^{+/+ }}$ kidneys with four kidneys from mice which were wild type at the both the cpk and Frem 2 loci. However, there were no significant differences between polycystic and non-cystic kidneys in the expression levels of Frem1 $(P=0.9)$, Frem 2 $(P=0.5)$ or Grip1 $(P=0.3)$. Levels of Frem 3 transcripts were markedly and significantly $(12.4$-fold; $P=0.001)$ downregulated in $c p k / c p k$ versus non-cystic kidneys.

Expression of FS molecules in polycystic kidney epithelia

We crossed the Frem $2^{\text {LacZ }}$ allele into $c p k$ mice and examined the kidneys of $c p k / c p k$ mice which also carried one LacZ allele. The transgene was expressed in epithelia of small cortical cysts (Fig. 3a, b) and - but only faintly - in massive cysts deeper in the organ (Fig. 3c). Undilated tubules between cysts strongly expressed Frem 2/LacZ (Fig. 3c, d). In histology sections of $c p k / c p k$ kidneys, there was no significant difference between the area occupied by cysts in $\mathrm{Frem}^{+/+}$ organs $(65 \pm 11 \% ; n=9)$ compared with Frem $^{\text {LacZ/+ }}(62 \pm$ $6 \% ; n=8)$ organs. In sections of wild-type mouse kidneys aged 14 days, Fras 1 was immunodetected in cortical and medullary tubules with collecting duct profiles (Fig. 3e, f). In postnatal day-14 $\mathrm{cpk} / \mathrm{cpk} \mathrm{Frem} 2^{+/+}$kidneys, intense Fras1 immunoreactivity was noted in cyst epithelia (Fig. 3g). In sections of $c p k / c p k$ Frem $2^{\text {LacZ/+ }}$ kidneys treated with X-gal and then immunostained for Fras1, it was apparent that undilated tubules between cysts expressed Frem 2 but not Fras1 (Fig. 3d). Sections of $c p k / c p k$ Frem $2^{+/+}$polycystic kidneys which had undergone identical immunohistochemical procedures but with the primary antibody omitted showed, as expected, no signals (Fig. 3h). Fras1 was also immunodetected in cystic kidney epithelia within dexamethasone- 


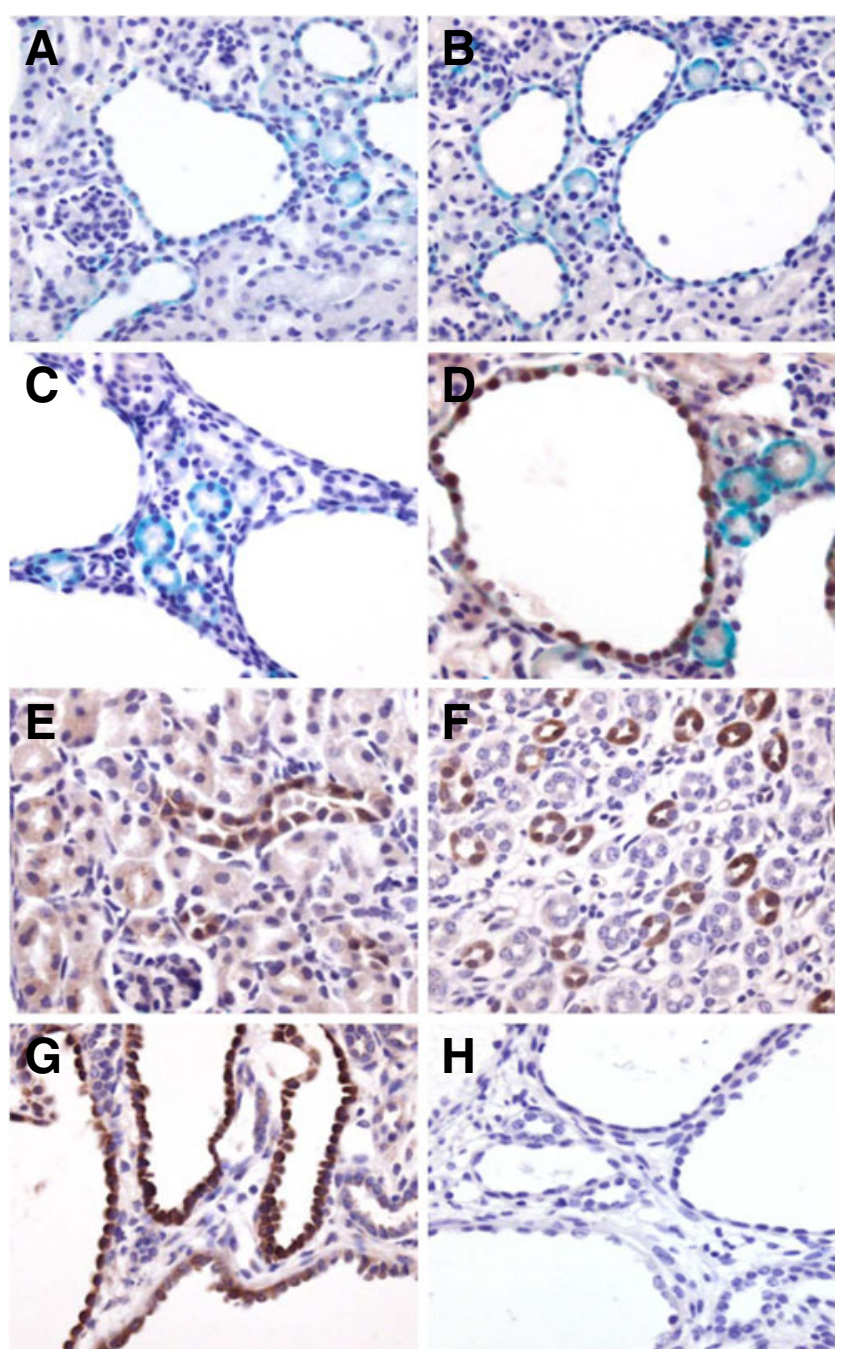

Fig. 3 Fraser syndrome gene expression in congenital polycystic kidneys (cpk). All frames depict histology sections cut from whole mounts which had been reacted with X-gal to detect LacZ reporter gene expression. All images show postnatal day-14 $c p k / c p k$ kidneys apart from $\mathbf{e}$ and $\mathbf{f}$ which are images of kidneys from non-cpk littermates. Organs depicted in a-d are from mice which also carry one Frem $2^{\text {Lac } Z}$ allele, whereas organs depicted in $\mathbf{e}-\mathbf{h}$ are from mice which are wild type at the Frem 2 locus. $\mathbf{d}-\mathbf{h}$ Sections were immunostained for Fras1, but the primary antibody was omitted in $\mathbf{h}$. a, b. Frem $2 /$ LacZ expression (light blue) in small cortical cysts. $\mathbf{c}$ Less marked transgene expression in attenuated epithelia lining massive cysts deep in the $c p k$ kidney. c, d, note that undilated tubules between large cysts express Frem $2 /$ LacZ. e, f Fras1 was immunodetected (brown) in subsets of cortical and medullary tubules in non-cystic kidneys. d, g Fras1 was intensely expressed in cystic epithelia within $c p k$ kidneys. In $\mathbf{d}$, note that undilated tubules between cysts express Frem2/LacZ but not Fras1, a result supporting the notion that the Fras1 antibody is non-reactive to Frem 2 and specific for Fras1. In $\mathbf{e}-\mathbf{h}$, no (light blue) X-gal reactivity was detected in these kidneys from mice which did not carry the Frem $2^{\text {LacZ }}$ allele. No immunohistochemical (brown) signal was found when the primary antibody to Fras1 was omitted (h). Magnification of all images $\times 40$

exposed explanted wild-type metanephroi and in larger cysts, most likely collecting-duct derived structures [25], in the deep cortex and outer medulla of adult PCK kidneys (Fig. 4).

\section{Discussion}

Fras 1 and Frem 2 transcripts are known to be expressed in the E11 mouse UB [6, 8], and previous studies have immunodetected Fras1 in UB epithelia [7, 8]. In Fras1 null mutant embryos generated on a C57BL-6 J background, the UB fails to penetrate renal mesenchyme, and this is followed by apoptotic involution of the rudiment [5, 8]. Fras 1 transcripts are also expressed in vesicles and S-shaped bodies, early nephron structures and podocytes of foetal glomeruli [8]. Notably, in outbred adult mice with compound Fras1/ Frem 2 mutations, kidneys contain multiple cysts lined by apoptotic and proliferative epithelia [6], and the same organs contain glomeruli with perturbed nephrin, podocin, integrin $\alpha 3$ and fibronectin expression [8].

Together, these previous observations lead to the hypothesis that Fras 1 and Frem 2 genes maintain the integrity of diverse renal epithelia as well as being involved in the initiation of the metanephric kidney. Until the study reported here, however, little data have been available on the expression of FS family molecules from late gestation through to postnatal maturation. We found that Frem 2 has a complex and dynamic expression pattern in maturing nephrons, including transient podocyte expression, and that it is expressed in both maturing and adult collecting ducts. Furthermore, Fras1 protein was detected in postnatal collecting ducts. A difference between expression of the two genes was that only Frem 2 was found in the smooth muscle of arterial walls; apart from this, at least within normal kidneys, the expression of both these FS molecules is epithelial-specific.

In our study, we measured glomerular numbers in postnatal kidneys and found that Frem 2 heterozygous mice did not have a significantly different result compared with wild-type littermates. We used an acid dissociation technique [23] rather than a non-biased sterology method for counting glomeruli [30]. Although the latter is considered the "gold standard", given that tissue architecture was similar in the heterozygous and wild-type mouse kidneys, the counts using the acid dissociation method can be interpreted to mean that Frem 2 halploinsuficiency is unlikely to confer an important difference in numbers. Very recently, a heterozygous missense FREM2 mutation has been reported in a patient with unilateral renal agenesis [31]. In the context of our study of heterozygous Frem 2 mutant mice in the C57BL-6 J background, we have yet to observe either unilateral or bilateral absent kidneys on autopsy. It remains possible that haploinsufficiency of Frem 2 might cause renal malformations in mice of different background strains, or that the missense FREM2 change reported in a patient with agenesis [31] could be operating in a dominant-negative manner. An alternative explanation for the human finding is that the FREM2 missense change simply represents a rare, non-pathogenic variant found by co-incidence in an individual with agenesis. 


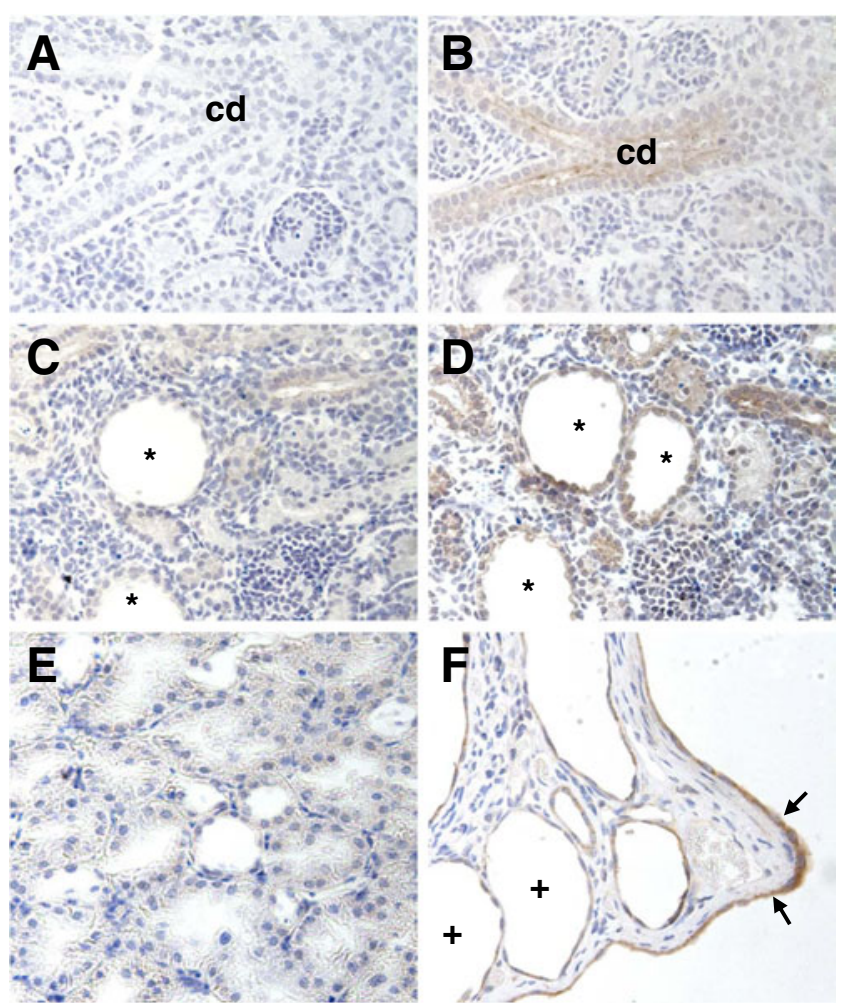

Fig. 4 Fras 1 immunohistochemistry in dexamethasone-induced and Pkhd1 mutant mice (PCK) cysts, a model of polycystic kidney disease. All sections were counterstained with haematoxylin (blue nuclei). Organs depicted in a-d are wild-type mouse metanephric organ cultures, with $\mathbf{a}$ and $\mathbf{b}$ grown in vehicle-only and $\mathbf{c}$ and $\mathbf{d}$ exposed to dexamethasone. a and $\mathbf{c}$ Primary antibody was omitted, and no significant immunohistochemical (brown) signal was detected in normal structures or cysts (asterisks). In explants grown in vehicle only (b), weak Fras1 signal was noted in branching collecting ducts $(c d)$. d Fras1 was immunodetected in epithelia of dexamethasone-induced cysts (asterisks). e Adult wild-type rat kidney; no significant Fras1 signal was detected. f PCK kidneys; smaller cysts $(+)$ displayed minimal Fras1 immunostaining, while a prominent signal appeared in epithelia lining large cysts (arrows). Magnification of all images $\times 40$

As discussed in the Introduction, Fras 1 and Frem 2 code for basement membrane-associated proteins $[9,10]$. Notably, there exists a human genetic disease called HANAC (hereditary angiopathy with nephropathy, aneurysms and muscle cramps) syndrome in which the dominant mutation of another basement membrane gene, COL4A1, coding for procollagen type IV $\alpha 1$, is associated with the postnatal growth of kidney cysts [32]. In this disease, tubule dilatation is perhaps triggered by weakened physical support conferred by a defective basement membrane, and it is possible that this change serves as a paradigm for cystogenesis associated with Fras $1 /$ Frem 2 mutations. Previous studies have shown that the manipulation of specific genes expressed in $c p k$ kidney epithelia can modify the size of kidney cysts. As examples, haploinsufficiency of the Paired box-2 transcription factor reduces cystogenesis, probably by enhancing apoptosis in cystic epithelia [33], whereas genetic downregulation of galectin-3, a secreted molecule located in the cilia and basal surfaces of collecting ducts, increases cyst growth by unknown mechanisms [21].

Based on the fact that Fras 1/Frem 2 mice can have cystic kidneys [6], and our current observations that (especially non-massive and thus presumably growing) cysts in $c p k / c p k$ kidneys clearly express Frem 2, we predicted that a reduction in expression level of Frem 2 might lead to a more severe cystic phenotype. This was not, however, found to be the case, at least as assessed by the measurement of kidney cross-sectional areas occupied by cysts in 14-day-old mice. Perhaps a more profound experimental reduction of Frem 2 expression would affect $c p k$ cystogenesis but because homozygous null mutant Frem 2 mice do not develop kidneys, this idea can not be tested with the experimental tools currently available to us.

Fras 1 transcripts were significantly upregulated in $c p k / c p k$ kidneys compared with those of non-cystic littermates. A trivial explanation for increased Fras 1 mRNA levels would be that, at 14 days of age, a greater proportion of the polycystic kidney is occupied by collecting duct epithelia compared with a non-cystic organ and that collecting ducts normally express this gene. On the other hand, we also found that Fras1 was immunolocalised in $c p k$ cysts, with intense signals. Having made this observation, we undertook Fras1 immunostaining in two other renal cystic models and detected the protein in dexamethasoneinduced cysts in explanted wild-type organs and in larger cysts in the PCK rat model of human ARPKD. These observations, namely, that Fras 1 is expressed in diverse models of kidney cysts, can be interpreted in two ways. Firstly, Fras 1 expression may be an unspecific reaction in cystic epithelia. Alternatively, Fras1 may be playing active roles in the biology of cyst growth. In the current study, we did not have access to a reliable antibody to Frem2, and thus could not determine Frem2 tissue localisation in the two extra models.

Finally, of note, $c p k / c p k$ kidneys showed marked downregulation of the Fras family gene, Frem3. Although the function of this gene in mammals is yet to be defined, it has been reported that the protein is widely expressed in basement membranes [10,17] and that frem 3 is required for skin integrity in embryonic fish [34].

Collectively, the results of our study are consistent with the hypothesis that FS family molecules may play roles in diverse kidney epithelia. In future studies, this contention would be best tested by conditional deletion of specific genes in specific nephron segments [35] and collecting ducts [36] in healthy and cystic kidneys. 
Acknowledgements LK was supported by a Medical Research Council Clinical Research Training Fellowship (G0601337). DAL is supported by a Kidney Research UK Senior Non-Clinical Training Fellowship and by a MRC New Investigator Award. MK-J is supported by a project grant from Kidney Research UK. ASW and CA are supported by the Manchester NIHR Biomedical Research Centre. ASW and PJS acknowledge grant support from the Wellcome Trust (085077). We thank Paul Winyard for provision of $c p k$ founder mice.

Disclosures None

\section{References}

1. Online Mendelian Inheritance in Man. Available at: http://www. ncbi.nlm.nih.gov/omim/219000. Accessed 23 May 2011

2. Slavotinek AM, Tifft CJ (2002) Fraser syndrome and cryptophthalmos: review of the diagnostic criteria and evidence for phenotypic modules in complex malformation syndromes. J Med Genet 39:623-633

3. van Haelst MM, Scambler PJ, Fraser Syndrome Collaboration Group, Hennekam RC (2007) Fraser syndrome: a clinical study of 59 cases and evaluation of diagnostic criteria. Am J Med Genet A 143A:3194-3203

4. Impallomeni M, Subramanian D, Mahmood N, Joseph I (2006) Fraser syndrome in a 96-year-old female. Age Ageing 35:642-643

5. McGregor L, Makela V, Darling SM, Vrontou S, Chalepakis G, Roberts C, Smart N, Rutland P, Prescott N, Hopkins J, Bentley E, Shaw A, Roberts E, Mueller R, Jadeja S, Philip N, Nelson J, Francannet C, Perez-Aytes A, Megarbane A, Kerr B, Wainwright B, Woolf AS, Winter RM, Scambler PJ (2003) Fraser syndrome and mouse blebbed phenotype caused by mutations in FRAS1/ Fras 1 encoding a putative extracellular matrix protein. Nat Genet 34:203-208

6. Jadeja S, Smyth I, Pitera JE, Taylor MS, van Haelst M, Bentley E, McGregor L, Hopkins J, Chalepakis G, Philip N, Perez-Aytes A, Watt FM, Darling SM, Jackson I, Woolf AS, Scambler PJ (2005) Identification of a new gene mutated in Fraser syndrome and mouse myelencephalic blebs. Nat Genet 37:520-525

7. Vrontou S, Petrou P, Meyer BI, Galanopoulos VK, Imai K, Yanagi M, Chowdhury K, Scambler PJ, Chalepakis G (2003) Fras1 deficiency results in cryptophthalmos, renal agenesis and blebbed phenotype in mice. Nat Genet 34:209-214

8. Pitera JE, Scambler PJ, Woolf AS (2008) Fras1, a basement membrane-associated protein mutated in Fraser syndrome, mediates both the initiation of the mammalian kidney and the integrity of renal glomeruli. Hum Mol Genet 17:3953-3964

9. Short K, Wiradjaja F, Smyth I (2007) Let's stick together: the role of the Fras1 and Frem proteins in epidermal adhesion. IUBMB Life 59:427-435

10. Pavlakis E, Chiotaki R, Chalepakis G (2011) The role of Fras1/ Frem proteins in the structure and function of basement membrane. Int J Biochem Cell Biol 43:487-495

11. Takamiya K, Kostourou V, Adams S, Jadeja S, Chalepakis G, Scambler PJ, Huganir RL, Adams RH (2004) A direct functional link between the multi-PDZ domain protein GRIP1 and the Fraser syndrome protein Fras1. Nat Genet 36:172-177

12. Long J, Wei Z, Feng W, Yu C, Zhao YX, Zhang M (2008) Supramodular nature of GRIP1 revealed by the structure of its PDZ12 tandem in complex with the carboxyl tail of Fras1. J Mol Biol 375:1457-1468

13. Kiyozumi D, Osada A, Sugimoto N, Weber CN, Ono Y, Imai T, Okada A, Sekiguchi K (2005) Identification of a novel cell- adhesive protein spatiotemporally expressed in the basement membrane of mouse developing hair follicle. Exp Cell Res 306:9-23

14. Kiyozumi D, Sugimoto N, Sekiguchi K (2006) Breakdown of the reciprocal stabilization of QBRICK/Frem1, Fras1, and Frem2 at the basement membrane provokes Fraser syndrome-like defects. Proc Natl Acad Sci USA 103:11981-11986

15. Smyth I, Du X, Taylor MS, Justice MJ, Beutler B, Jackson IJ (2004) The extracellular matrix gene Frem1 is essential for the normal adhesion of the embryonic epidermis. Proc Natl Acad Sci USA 101:13560-13565

16. Alazami AM, Shaheen R, Alzahrani F, Snape K, Saggar A, Brinkmann B, Bavi P, Al-Gazali LI, Alkuraya FS (2009) FREM1 mutations cause bifid nose, renal agenesis, and anorectal malformations syndrome. Am J Hum Genet 85:414-418

17. Petrou P, Pavlakis E, Dalezios Y, Chalepakis G (2007) Basement membrane localization of Frem3 is independent of the Fras1/ Frem1/Frem2 protein complex within the sublamina densa. Matrix Biol 26:652-658

18. Hou X, Mrug M, Yoder BK, Lefkowitz EJ, Kremmidiotis G, D'Eustachio P, Beier DR, Guay-Woodford LM (2002) Cystin, a novel cilia-associated protein, is disrupted in the cpk mouse model of polycystic kidney disease. J Clin Invest 109:533-540

19. Nakanishi K, Sweeney WE Jr, Zerres K, Guay-Woodford LM, Avner ED (2000) Proximal tubular cysts in fetal human autosomal recessive polycystic kidney disease. J Am Soc Nephrol 11:760763

20. Yuan H-T, Suri C, Landon DN, Yancopoulos GD, Woolf AS (2000) Angiopoietin-2 is a site specific factor in differentiation of mouse renal vasculature. J Am Soc Nephrol 11:1055-1066

21. Chiu MG, Johnson TM, Woolf AS, Dahm-Vicker EM, Long DA, Guay-Woodford L, Hillman KA, Bawumia S, Venner K, Hughes RC, Poirier F, Winyard PJ (2006) Galectin-3 associates with the primary cilium and modulates cyst growth in congenital polycystic kidney disease. Am J Pathol 169:1925-1938

22. Chan S-K, Riley PR, Price KL, McElduff F, Winyard PJ, Welham SJ, Woolf AS, Long DA (2010) Corticosteroid-induced kidney dysmorphogenesis is associated with deregulated expression of known cystogenic molecules, as well as indian hedgehog. Am J Physiol Renal Physiol 298:F346-F356

23. Welham SJM, Riley PR, Wade A, Hubank M, Woolf AS (2005) Maternal diet programs embryonic kidney gene expression. Physiol Genomics 22:48-56

24. Woolf AS (2010) Environmental influences on renal tract development: a focus on maternal diet and the glucocorticoid hypothesis. Klin Padiatr [Suppl 1]:S10-S17

25. Lager DJ, Qian Q, Bengal RJ, Ishibashi M, Torres VE (2001) The pck rat: a new model that resembles human autosomal dominant polycystic kidney and liver disease. Kidney Int 59:126-136

26. Ward CJ, Hogan MC, Rossetti S, Walker D, Sneddon T, Wang X, Kubly V, Cunningham JM, Bacallao R, Ishibashi M, Milliner DS, Torres VE, Harris PC (2002) The gene mutated in autosomal recessive polycystic kidney disease encodes a large, receptor-like protein. Nat Genet 30:259-269

27. Hartman HA, Lai HL, Patterson LT (2007) Cessation of renal morphogenesis in mice. Dev Biol 310:379-387

28. Woolf AS, Pitera JE (2009) Embryology. In: Avner ED, Harmon WE, Niaudet P (eds) Pediatric nephrology, 6th edn. Springer SBM, Heidelberg, pp 3-30

29. Hillman KA, Johnson TM, Winyard PJD, Burnstock G, Unwin RJ, Woolf AS (2002) $\mathrm{P} 2 \mathrm{X}_{7}$ receptors are expressed during mouse nephrogenesis and in collecting duct cysts of the $\mathrm{cpk} / \mathrm{cpk}$ mouse. Exp Nephrol 10:34-42

30. Cullen-McEwen LA, Drago J, Bertram JF (2001) Nephron endowment in glial cell line-derived neurotrophic factor (GDNF) heterozygous mice. Kidney Int 60:31-36 
31. Saisawat P, Tasic V, Vega-Warner V, Kehinde EO, Günther B, Airik R, Innis JW, Hoskins BE, Hoefele J, Otto EA, Hildebrandt F (2012) Identification of two novel CAKUT-causing genes by massively parallel exon resequencing of candidate genes in patients with unilateral renal agenesis. Kidney Int 81:196-200

32. Plaisier E, Gribouval O, Alamowitch S, Mougenot B, Prost C, Verpont MC, Marro B, Desmettre T, Cohen SY, Roullet E, Dracon M, Fardeau M, Van Agtmael T, Kerjaschki D, Antignac C, Ronco P (2007) COL4A1 mutations and hereditary angiopathy, nephropathy, aneurysms, and muscle cramps. N Engl J Med 357:2687-2695

33. Ostrom L, Tang MJ, Gruss P, Dressler GR (2000) Reduced Pax2 gene dosage increases apoptosis and slows the progression of renal cystic disease. Dev Biol 219:250-258
34. Carney TJ, Feitosa NM, Sonntag C, Slanchev K, Kluger J, Kiyozumi D, Gebauer JM, Coffin Talbot J, Kimmel CB, Sekiguchi K, Wagener R, Schwarz H, Ingham PW, Hammerschmidt M (2010) Genetic analysis of fin development in zebrafish identifies furin and hemicentin 1 as potential novel Fraser syndrome disease genes. PLoS Genet 6:e1000907

35. Heikkilä E, Juhila J, Lassila M, Messing M, Perälä N, Lehtonen E, Lehtonen S, Sjef Verbeek J, Holthofer H (2010) $\beta$-Catenin mediates adriamycin-induced albuminuria and podocyte injury in adult mouse kidneys. Nephrol Dial Transplant 25:2437-2446

36. Ronzaud C, Loffing J, Gretz N, Schütz G, Berger S (2011) Inducible renal principal cell-specific mineralocorticoid receptor gene inactivation in mice. Am J Physiol Renal Physiol 300:F756-F760 